\title{
Vibration effects on colloidal three-phase systems
}

\author{
Andrei Gerasimov ${ }^{1}$, Olga Eremina ${ }^{2}$, Victoria Lazareva ${ }^{3}$, Alexandra Yasinskaya ${ }^{4}$ \\ REC "Mekhanobr-Tekhnika”, Saint Petersburg, Russia \\ ${ }^{1}$ Corresponding author \\ E-mail: ${ }^{1}$ gerasimov_am@mtspb.com, ${ }^{2}$ eremina_ov@mtspb.com, ${ }^{3}$ lazareva_vv@mtspb.com, \\ ${ }^{4}$ yasinskaya_av@mtspb.com \\ Received 5 June 2020; accepted 18 June 2020 \\ DOI https://doi.org/10.21595/vp.2020.21546 \\ Check for updates \\ Copyright $(2020$ Andrei Gerasimov, et al. This is an open access article distributed under the Creative Commons Attribution License, \\ which permits unrestricted use, distribution, and reproduction in any medium, provided the original work is properly cited.
}

\begin{abstract}
Flotation and foam separation processes are used in the beneficiation of ores containing layered silicates. The difficulties that arise with such beneficiation can complicate the overall concentration process. It is important that the process of flotation and foam separation occur under conditions of initiated or simultaneously imposed vibration. Such vibration can affect the behavior of the suspension (negatively or positively). Studying the vibration parameters applied to the suspension can help solve technological problems that arise during the concentration of ores containing layered silicates. In the present work, the behavior of a three-phase colloidal system under conditions of oscillation of a vessel with an external vibration exciter is studied.
\end{abstract}

Keywords: three-phase systems, flotation, vibration effect, foam structure, hydrophilic, hydrophobic.

\section{Introduction}

Clay minerals can cause a variety of problems of beneficiation. The mild nature of these minerals leads to the formation of large amounts of slimes. The presence of a negative effect on the rheology of sediment adversely affects both flotation and grinding. The presence of a hydrophilic sediment also leads to the formation of slime coatings and high amounts of entrainment in flotation.

The slimes resulting from ores that contain large amounts of clay minerals and produce large amounts of very tiny particles. This is typically attributed to the soft nature of the clay minerals, where they get preferentially ground compared to harder mineral particles.

The effect of sludge on flotation is known as slime coatings. In this phenomenon, relatively large valuable particles are completely or partially covered by layered hydrophilic sludge, which makes valuable hydrophilic and prevents the adsorption of the collector $[1,2]$.

The mechanism of coating by slimes has been widely studied. Earlier work postulated that the slime coatings attached to mineral particles through chemisorptions, resulting from the ion exchange between slime particles and the surrounding solution. However, the current consensus is that slime coatings arise due to electrostatic forces between oppositely charged mineral particles $[1,3]$. The study [4] inferred that fine kaolinite particles were forming hydrophilic coatings on chalcopyrite surfaces at low $\mathrm{pH}$ values, where chalcopyrite becomes less negatively charged, thus significantly retarding flotation.

The stability of flotation foam is an important property that has a strong influence on the overall productivity of flotation through $[4,5]$. Froth stability is difficult to define, but can be generally described as the measure of a rate at which bubbles coalesce within the froth structure. On the other hand, froth mobility can be described as a rate at which the froth overflows the cell weir.

Stable froths are generally characterized by reduced mobility [6]. Low mobility prevents effective froth overflow into the collection launders, with detrimental effects on flotation recovery. The quality of the foam product decreases with slower drainage due to the high stability of the foam. In most cases, optimum froth stability is desired; as opposed to a highly stable or unstable regime to balance the loss of valuable particles through drop- pack with the removal of entrained 
material though drainage.

One of the major factors influencing the stability of flotation froths is the presence of mineral particles and their properties [7]. It is generally agreed that the size of particles and their hydrophobicity/hydrophilicity important properties in determining the degree of stabilization of the foam by solid particles.

Flotation froths tended to become highly stable and unmanageable in the presence of large quantities of fine hydrophobic particles [8]. The particle stabilizing effect was far more prevalent in the presence of laminar (plate- like) particles rather than spherical ones. This further reinforces the notion that platy, hydrophobic phyllosilicate particles are likely to contribute to the formation of highly stable flotation froths, and hence have a detrimental effect on drainage and froth recovery. This description correlates well with the type of slimes generated in the presence of clay minerals such as hydrophobic talc.

This study presents an assessment of the behavior of hydrophobic / hydrophilic particles in a colloidal system under different oscillations of the vessel. The study was conducted monitoring the distribution of levels depending on its geometric shapes, hydration properties and frequency of the vibration stand.

\section{Methods and materials}

Glass objects of spherical shape with a diameter of $3 \mathrm{~mm}$ and a cubic shape, the rib length of which was also $3 \mathrm{~mm}$, were used as objects simulating the behavior of particles in dispersed media. The hydration properties of the surface were changed by treating the initial objects with aerosols, which include substances that form a hydrophilic or hydrophobic film on the surface of the objects. The index of hydration properties was determined according to the values of the contact angle in the liquid-solid system [9]. To form a hydrophilic surface, the objects were treated with acrylic water-dispersed paint based on polymers of methyl, ethyl and butyl acrylates $\left(\theta=60^{\circ}\right)$. A hydrophobic surface was obtained by treating objects with a paraffin-based spray $\left(\theta=110^{\circ}\right)$.

Sodium oleate, one of the most common flotation collector reagents with strong foaming properties, was chosen as a surfactant [10]. The sodium oleate used in this work was obtained by saponification of oleic acid with sodium hydroxide. For experimental studies, a solution of a concentration of $200 \mathrm{mg} / \mathrm{L}$ was used.

The foam layer was obtained in a glass chamber with a cross section of $49 \mathrm{~cm}^{2}$ using a Ross-Miles device. The behavior of particles in the foam layer was controlled in two modes: static and dynamic. An experimental study in dynamic mode was carried out using a universal vibration stand (Fig. 1) at a frequency of 20,30,35, 40, and $50 \mathrm{~Hz}$, respectively. The behavior of particles in the system was recorded by a high-speed Evercam 4000-32-M camera.

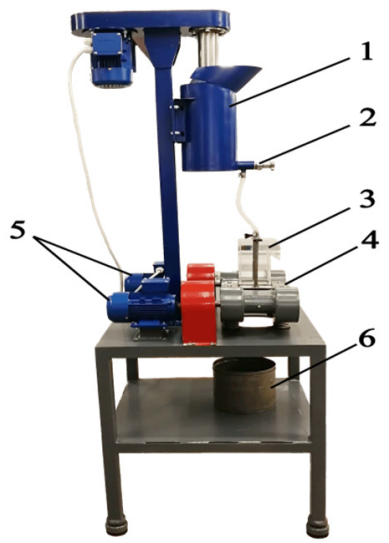

Fig. 1. General view of the experimental stand: 1 - conditioning tank, 2 - shut-off fitting, 3 interchangeable chamber, 4 - vibrating platform, 5 - vibration drives, 6 - material collecting tank 


\section{Results}

The experiment showed:

1. The rate of passage of hydrophobic particles through the foam layer decreases with increasing vibration frequency of the stand;

2. The minimum speed of hydrophobic particles in the foam layer is observed at high frequencies $(50 \mathrm{~Hz})$;

3. At a frequency of $40 \mathrm{~Hz}$, hydrophobic particles stuck in the foam layer;

4. The maximum particle velocity in the foam layer is observed at low frequencies $(20 \mathrm{~Hz})$;

5 . The speed of passage of hydrophilic particles through the foam layer with an increase in the vibration frequency of the stand first decreases to a minimum value, and then increases;

6 . The minimum speed of hydrophilic particles in the foam layer is observed at medium frequencies $(30-40 \mathrm{~Hz})$;

7. The frequency of jamming of hydrophilic particles in the foam layer is higher than that of hydrophobic (Fig. 2);

8. The speed of hydrophobic particles in the foam layer at low and medium frequencies is higher than the speed of hydrophilic particles;

9. At high frequencies of $50 \mathrm{~Hz}$, there is a discrepancy in the rate of hydrophilic and hydrophobic particles. The speed of hydrophilic particles at a frequency of $50 \mathrm{~Hz}$ is higher than the speed of hydrophobic ones;

10. The speed of cubic hydrophilic particles at $50 \mathrm{~Hz}$ is 2 times higher than the speed of spherical;

11. The speed of cubic particles, regardless of the surface properties in the foam layer, is higher than the velocity of spherical;

12. The speed of the elements in the foam layer can be distributed in the following order: spherical hydrophilic $<$ spherical hydrophobic $<$ cubic hydrophilic $<$ cubic hydrophobic.

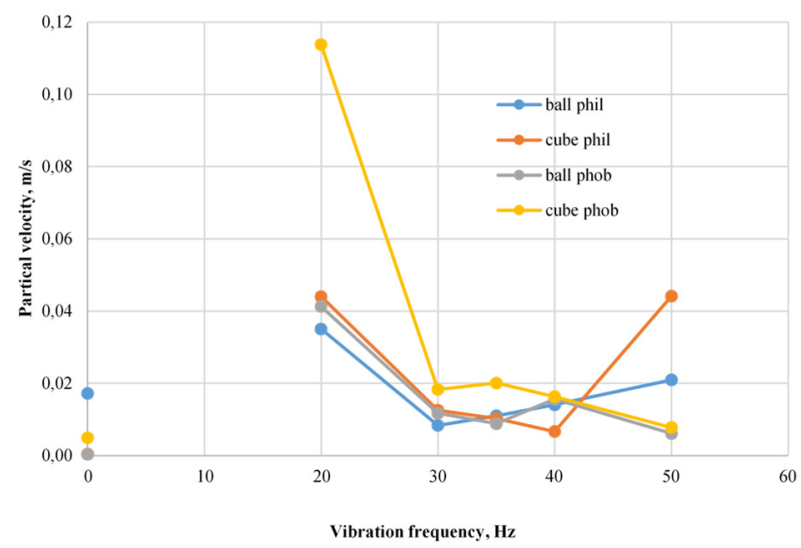

Fig. 2. Particle velocity in the foam layer

\section{Conclusions}

The presence of layered silicates with mobile crystalline lattices in the extracted ores significantly complicates their enrichment using both "wet" and "dry" processing. In case the ores contain swelling clay minerals, these ores often turn into a "nightmare", for the processing specialists.

The obtained practical data will be of interest for further theoretical study and improvement of technological processes for the processing of layered silicates by the method of flotation and foam separation and in the flotation treatment of wastewater.

By controlling the parameters of vibration on a three-phase colloidal system, it is possible to 
maintain the desired technological parameters of beneficiation. This experiment will allow us to give an additional version of theoretical research and the subsequent design of vibration devices.

\section{Acknowledgements}

The study has been carried out using a grant from the Russian Science Foundation (project 17-79-30056). The Research Adviser for the Project is Academician of the Russian Academy of Sciences, Professor L.A. Vaisberg.

\section{References}

[1] Arnold B. J., Aplan F. F. The effect of clay slimes on coal flotation, part I: the nature of the clay. International Journal of Mineral Processing, Vol. 17, Issues 3-4, 1986, p. 225-242.

[2] Trahar W. J. A rational interpretation of the role of particle size in flotation. International Journal of Mineral Processing, Vol. 8, Issue 4, 1981, p. 289-327.

[3] Shi F. N., Zheng X. F. The rheology of flotation froths. International Journal of Minerals Processing, Vol. 69, Issues 1-4, 2003, p. 115-128.

[4] Forbes E., Davey K. J., Smith L. Decoupling rheology and slime coatings effect on the natural flotability of chalcopyrite in a clay- rich flotation pulp. Minerals Engineering, Vol. 56, 2014, p. 136-144.

[5] Rubenstein J. B., Melik- Gaikazyan V. I. Characterisation of flotation froths. Frothing in Flotation II, Gordon \& Breach, Amsterdam, 1998.

[6] Moolman D. W., Eksteen J. J., Aldrich C., van Deventer J. S. J. The significance of flotation froth appearance for machine vision control. International Journal of Mineral Processing, Vol. 48, Issues 3-4, 1996, p. 135-158.

[7] Tao D., Luttrell G. H., Yoon R. H. A parametric study of froth stability and its effect on column flotation of fine particles. International Journal of Mineral Processing, Vol. 59, Issue 1, 2000, p. 25-43.

[8] Lovell V. M. Froth Characteristics in Phosphate Flotation. Port City Press, Baltimore, 1976.

[9] Lisichkin G. V. Chemistry of Grafted Surface Compounds. FIZMATLIT, Moscow, 2003, p. 327.

[10] Arsentyev V. A., Gorlovsky S. I., Ustinov I. D. The Complex Effect of Flotation Reagents. Nedra, Moscow, 1992, p. 143. 